\title{
Brush-Painting and Photonic Sintering of Copper Oxide and Silver Inks on Wood and Cardboard Substrates to Form Antennas for UHF RFID Tags
}

\author{
Erja Sipilä, ${ }^{1}$ Johanna Virkki, ${ }^{1}$ Jianhua Wang, ${ }^{2}$ Lauri Sydänheimo, ${ }^{1}$ and Leena Ukkonen ${ }^{1}$ \\ ${ }^{1}$ Department of Electronics and Communications Engineering, Tampere University of Technology, \\ P.O. Box 692, 33101 Tampere, Finland \\ ${ }^{2}$ Faculty of Automation, Guangdong University of Technology, No. 100 Waihuan Xi Road, Guangzhou Higher Education Mega Center, \\ Panyu District, Guangzhou 510006, China
}

Correspondence should be addressed to Erja Sipilä; erja.sipila@tut.fi

Received 26 January 2016; Accepted 28 April 2016

Academic Editor: Miguel Ferrando Bataller

Copyright (C) 2016 Erja Sipilä et al. This is an open access article distributed under the Creative Commons Attribution License, which permits unrestricted use, distribution, and reproduction in any medium, provided the original work is properly cited.

\begin{abstract}
Additive deposition of inks with metallic inclusions provides compelling means to embed electronics into versatile structures. The need to integrate electronics into environmentally friendly components and structures increases dramatically together with the increasing popularity of the Internet of Things. We demonstrate a novel brush-painting method for depositing copper oxide and silver inks directly on wood and cardboard substrates and discuss the optimization of the photonic sintering process parameters for both materials. The optimized parameters were utilized to manufacture passive ultra high frequency (UHF) radio frequency identification (RFID) tag antennas. The results from wireless testing show that the RFID tags based on the copper oxide and silver ink antennas on wood substrate are readable from ranges of 8.5 and 11 meters, respectively, and on cardboard substrate from read ranges of 8.5 and 12 meters, respectively. These results are well sufficient for many future wireless applications requiring remote identification with RFID.
\end{abstract}

\section{Introduction}

Material choices in future wireless components and devices will have a huge effect on the environment and consequently the use of biodegradable, environment-friendly substrate materials, for example, cardboard, wood, textile, and paper, has been an increasing trend in electronics during the recent years [1-5]. In addition, the concept of embedding electronics as a part of versatile structures offers potential for novel applications and many industries are interested in these smart products. For example, cardboard is anindispensable material in the packaging and graphics industry, which also makes it an interesting substrate material for electronics, especially considering low cost electronics [6]. Great possibilities also lie in the construction industry, where wood is a typical material, as well as in the plywood industry itself $[7,8]$.

Excessive potential for future environmentally friendly wireless applications can be found from passive ultra high frequency (UHF) radio frequency identification (RFID) technology. Passive UHF RFID technology provides a method for automatic identification and tracking of items with batteryfree remotely addressable electronic tags composed of an antenna and an integrated circuit (IC). The use of propagating electromagnetic waves in the UHF regime for powering and communicating with the passive tags enables rapid interrogation of a large quantity of tags through various media [9]. In comparison to barcodes, IC-enabled RFID tags allow the data stored in them to be updated wirelessly at any time. Thanks to the energy efficient mechanism of digitally modulated scattering utilized in the tag-to-reader wireless communication, the data can be read from a distance of several meters. This makes passive UHF RFID tags an interesting technology to be used as "proof of concept" for future environmentally friendly electronics [10, 11]. For further information on RFID technology, a survey of the history of RFID is presented in [12] and an introduction to today's systems, especially to 


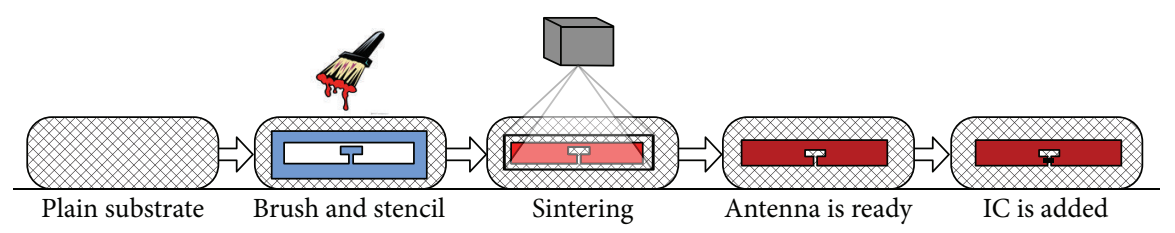

FIGURE 1: Brush-painting process.

passive UHF RFID technology used in this study, is provided in $[13,14]$. Finally, a thorough introduction of the design of antennas for RFID tags can be found in $[15,16]$.

In this study, the optimal photonic sintering parameters for brush-painted copper oxide and silver ink antennas on wood and cardboard substrates were studied. These sintering parameters were then used to manufacture environmentally friendly passive UHF RFID tag antennas. The work presented here is organized as follows. After Introduction, Section 2 introduces our tag design and the used brush-painting and sintering methods. Section 3 presents the actual tag fabrication with the optimized manufacturing parameters. The wireless tag measurements are introduced in Section 4. Section 5 presents the results and Section 6 summarizes the conclusions of this study.

\section{Brush-Painting and Photonic Sintering of Antennas}

Brush-painting is a versatile but simple and fast additive manufacturing method that can be integrated into manufacturing process of products incorporated with RFID tags. The method not only reduces process steps but also minimizes the need of conductive material, as the material is dispensed directly to the brush and from the brush directly to the antenna area in the substrate. This reduces costs and is more environment-friendly, especially when compared to the widely used etching process in RFID manufacturing. The brush-painting process steps are presented in Figure 1. Brush-painting has been previously successfully used for fabrication of tag antennas on fabric substrate with silver nanoparticle ink [1] and on wood substrate with silver and copper nanoparticle inks [2]. In this study, screen printable silver and copper oxide inks were used. The RFID tag manufacturing process for nanoparticle inks in study [2] and screen printable inks in this study is exactly the same. The only difference is in the photonic sintering parameters; the sintering parameters have to be chosen for every ink and material combination independently.

Copper and silver tag antennas were brush-painted through a stencil ( $50 \mu \mathrm{m}$ thick polyimide film) on wood and cardboard substrates, by using only one layer of ink. The wood substrate used in this study is $4 \mathrm{~mm}$ thick plywood with 3 wood layers and the cardboard is normal packaging cardboard. Wood and cardboard are lossy materials but due to the thin substrates they are not expected to affect the tag performance significantly. However, it can be assumed that the use environment, for example, varying moisture content, will influence the performance of RFID tags on

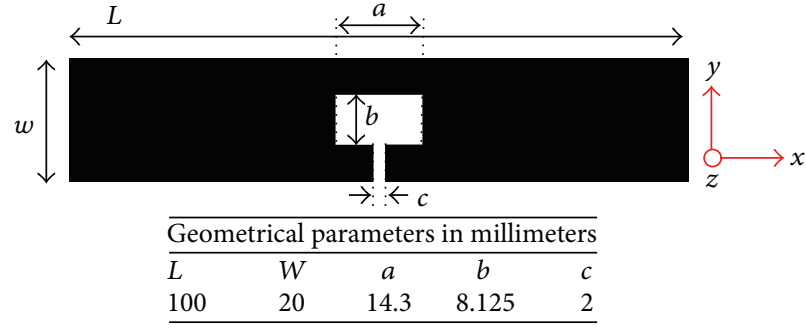

FIGURE 2: Studied tag antenna geometry.

wood and cardboard, as the tag antenna impedance and the ohmic losses are affected by the surrounding materials [17]. The next step, when continuing in this study area, is to use simulation methods to study the effects of the substrate thickness variation and the effects of different environmental stresses on the tag performance.

A compact tag antenna shown in Figure 2 was utilized as the antenna geometry. The simple antenna geometry was chosen for the prototype manufacturing purpose; it is not optimized to be used on wood or cardboard substrate. The used silver ink was Metalon HPS-021LV silver flake ink [18] and the used copper ink was Metalon ICI-021 copper oxide ink [19].

Heat sintering in an oven is nowadays commonly used in additive manufacturing. However, the needed sintering times are long and usually the needed temperatures are high. Flash lamp sintering is a photonic sintering method that in ambient conditions uses short light pulses from a flash lamp to heat the ink to a high enough temperature within few milliseconds $[2,20]$. Photonic sintering is advantageous in mass productions because of its extremely short process time together with the ability to be done in normal room conditions, which also allows the use of temperature sensitive substrate materials [21]. In addition to silver ink, photonic sintering also allows the use of more cost-effective copper ink, which cannot be sintered by heat sintering because of the insulating oxide formation during sintering process $[22,23]$. In this study, the photonic sintering was done using Xenon Sinetron 2010-L system, which provides a high energy pulsed light for sintering of conductive particles. The sintering system parameters are lamp voltage, flash pulse duration, and number of flash pulses. The lamp voltage can be adjusted between $1800 \mathrm{~V}$ and $3000 \mathrm{~V}$, in $50 \mathrm{~V}$ increments, and the pulse duration can be adjusted up to $2000 \mu$ s [24]. The energy of each flash pulse can be calculated using the following formula:

$$
E=\left(\frac{V}{3120}\right)^{2.4} \cdot t
$$


TABLE 1: Sintering parameters and resistance measurements.

\begin{tabular}{|c|c|c|c|c|c|c|}
\hline $\begin{array}{l}\text { Sample } \\
\text { number }\end{array}$ & $\begin{array}{c}\text { Substrate } \\
\text { material }\end{array}$ & Conductive ink & Sintering parameters & $\begin{array}{c}\text { Number of flash } \\
\text { pulses needed }\end{array}$ & $\begin{array}{c}\text { Light energy from } \\
\text { lamp [kJ] }\end{array}$ & Resistance $[\Omega]$ \\
\hline 1 & Wood & $\mathrm{Ag}$ & $1000 \mu \mathrm{s}, 2800 \mathrm{~V}$ & 3 & 2.314 & 1.1 \\
\hline 2 & Wood & $\mathrm{Ag}$ & $2000 \mu \mathrm{s}, 2200 \mathrm{~V}$ & 2 & 1.729 & 0.6 \\
\hline 3 & Wood & $\mathrm{Ag}$ & $2000 \mu \mathrm{s}, 2500 \mathrm{~V}$ & 2 & 2.350 & 0.5 \\
\hline 4 & Wood & $\mathrm{Ag}$ & $2000 \mu \mathrm{s}, 2800 \mathrm{~V}$ & 1 & 1.543 & 0.5 \\
\hline 5 & Wood & $\mathrm{Ag}$ & $2000 \mu \mathrm{s}, 3000 \mathrm{~V}$ & 1 & 1.820 & 0.4 \\
\hline 6 & Wood & $\mathrm{Cu}$ & $1500 \mu \mathrm{s}, 2600 \mathrm{~V}$ & 1 & 0.968 & 4.7 \\
\hline 7 & Wood & $\mathrm{Cu}$ & $2000 \mu \mathrm{s}, 2000 \mathrm{~V}$ & 3 & 2.064 & Not conducting \\
\hline 8 & Wood & $\mathrm{Cu}$ & $2000 \mu \mathrm{s}, 2200 \mathrm{~V}$ & 2 & 1.729 & 11.7 \\
\hline 9 & Wood & $\mathrm{Cu}$ & $2000 \mu \mathrm{s}, 2400 \mathrm{~V}$ & 1 & 1.066 & 5.0 \\
\hline 10 & Cardboard & $\mathrm{Ag}$ & $1000 \mu \mathrm{s}, 2800 \mathrm{~V}$ & 3 & 2.314 & 0.6 \\
\hline 11 & Cardboard & $\mathrm{Ag}$ & $2000 \mu \mathrm{s}, 2200 \mathrm{~V}$ & 2 & 1.729 & 0.7 \\
\hline 12 & Cardboard & $\mathrm{Ag}$ & $2000 \mu \mathrm{s}, 2500 \mathrm{~V}$ & 2 & 2.350 & 0.6 \\
\hline 13 & Cardboard & $\mathrm{Ag}$ & $2000 \mu \mathrm{s}, 2800 \mathrm{~V}$ & 1 & 1.543 & Not conducting \\
\hline 14 & Cardboard & $\mathrm{Cu}$ & $1500 \mu \mathrm{s}, 2600 \mathrm{~V}$ & 1 & 0.968 & 10.0 \\
\hline 15 & Cardboard & $\mathrm{Cu}$ & $2000 \mu \mathrm{s}, 2000 \mathrm{~V}$ & 2 & 1.376 & 9.7 \\
\hline 16 & Cardboard & $\mathrm{Cu}$ & $2000 \mu \mathrm{s}, 2200 \mathrm{~V}$ & 1 & 0.865 & 5.8 \\
\hline 17 & Cardboard & $\mathrm{Cu}$ & $2000 \mu \mathrm{s}, 2200 \mathrm{~V}$ & 2 & 1.729 & 10.5 \\
\hline 18 & Cardboard & $\mathrm{Cu}$ & $2000 \mu \mathrm{s}, 2400 \mathrm{~V}$ & 1 & 1.066 & Not conducting \\
\hline
\end{tabular}

where $E$ is the energy in Joules per pulse, $V$ is the voltage in Volts, and $t$ is the time in microseconds [24]. This is the energy that the lamp produces.

Despite the obvious advantages of photonic sintering, finding the optimized sintering parameters is the biggest challenge. Too high sintering voltage or too long pulse duration, in other words too high sintering energy, can directly damage the ink layer and the substrate [25], while too low sintering voltage and short time can lead to poor or partial sintering. In addition, the sintering parameters for each substrate and ink material need to be studied individually [25]. Incorrect placement of the tag antenna in the sintering device can also lead to poor sintering performance, either to partial sintering or to burned ink layer.

\section{Fabrication of Passive UHF RFID Tags}

The brush-painted antennas were sintered with Xenon Sinetron 2010-L system. In this study, the lamp voltage was changed from $2000 \mathrm{~V}$ to $3000 \mathrm{~V}$. The used pulse widths in tests were $1000 \mu \mathrm{s}, 1500 \mu \mathrm{s}$, and $2000 \mu \mathrm{s}$. Sintering was started with a single flash pulse. After sintering, a visual inspection together with preliminary resistance measurements was done and, based on these results, it was decided if sintering with two flash pulses should be tested. Similarly, the need for third flash pulse was decided after two flash pulses. If the results of visual inspection and resistance measurement were suitable already after one flash pulse, further flash pulses were not done, as the goal was to use as few flash pulses as possible. In addition, if it became clear after one flash pulse that the sintering energy was already too high, further sintering with more flash pulses was not done.

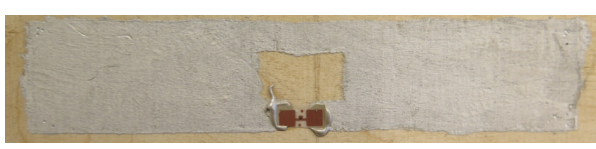

(a)

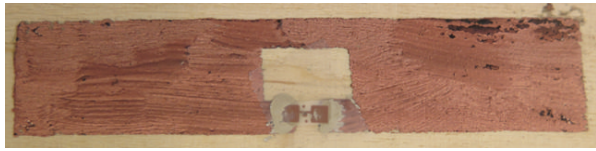

(b)

FIGURE 3: (a) Sample 4, a silver antenna on wood substrate, and (b) Sample 9, a copper antenna on wood substrate.

It was quickly discovered that $1000 \mu$ s and $1500 \mu$ s are too short pulse widths, which were not enough even after multiple flash pulses. Thus, we manufactured most of the samples using the maximum pulse width, $2000 \mu$ s.

The resistances of the sintered antennas were measured using a Fluke 115 multimeter. The measurement probes were placed in the opposite corners of the fabricated antenna. The measured resistances and the total flash light energy for antennas manufactured with different parameters can be seen in Table 1. The energy is calculated using (1). Based on the resistance measurements and visual inspection results, two best tag antennas from each of the 4 slots (copper/silver ink and cardboard/wood substrate) were chosen for wireless measurements. Figures 3 and 4 show sintered silver and copper antennas on wood and cardboard substrates, respectively.

All the tags fabricated with silver ink on wood substrate were found to show low resistances and very little variation 


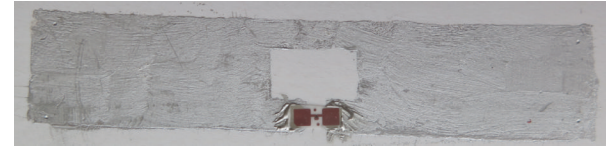

(a)

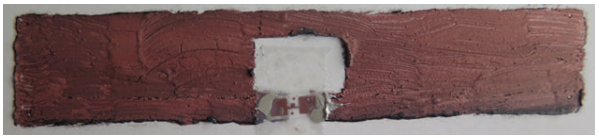

(b)

FIgURE 4: (a) Sample 10, a silver antenna on cardboard substrate, and (b) Sample 15, a copper antenna on cardboard substrate.

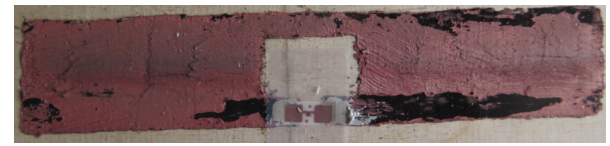

Figure 5: Burned areas on the antenna surface of Sample 6.

in resistance measurement results with different sintering parameters and different sintering energy (see Table 1). The highest resistance among silver ink antennas on wood substrate was $1.1 \Omega$, measured for Sample $1(1000 \mu \mathrm{s}, 2800 \mathrm{~V}, 3$ flash pulses). However, also this result would be low enough for a working UHF RFID tag antenna. By using 1 or 2 flash pulses with the same parameters the antenna was not fully sintered and residues of the nonsintered ink were seen. These results indicate that $1000 \mu \mathrm{s}$ is too short pulse width, especially as minimum number of flash pulses is desirable: the number of flash pulses has an effect on the process time and can be an essential factor in fast mass production of electronics. Sample $4(2000 \mu \mathrm{s}, 2800 \mathrm{~V}, 1$ flash pulse $)$ and Sample 5 (2000 $\mathrm{s}, 3000 \mathrm{~V}, 1$ flash pulse) were chosen to wireless measurements; they had the lowest resistance values, $0.5 \Omega$ and $0.4 \Omega$, respectively, with a minimum number of flash pulses.

The copper oxide ink antennas on wood substrate had a larger variation in resistances than the silver ink counterparts. In general, the copper oxide ink antennas also had higher resistance values than silver ink antennas, which correspond to materials' general conductivities $[18,19]$. Sample $6(1500 \mu \mathrm{s}$, $2600 \mathrm{~V}, 1$ flash pulse) and Sample $9(2000 \mu \mathrm{s}, 2400 \mathrm{~V}, 1$ flash pulse) showed the lowest resistances, $4.7 \Omega$ and $5.0 \Omega$, respectively, and they were chosen to further measurements. In addition to the lowest resistance values, they had the lowest total light energy but at the same time the highest light energy per one light pulse and higher sintering voltages than the other two samples in this test lot. Despite the lowest resistance measurement result, the surface of Sample 6 did not look as smooth as the surface of Sample 9: the surface of Sample 6 is partly oversintered and small burned areas can be seen on the surface (see Figure 5). This indicates that the sintering voltage has been little too high. Sample $7(2000 \mu \mathrm{s}, 2000 \mathrm{~V}, 3$ flash pulses) was not conductive at all, meaning the sintering power was too low initially. Even after 3 flash pulses the

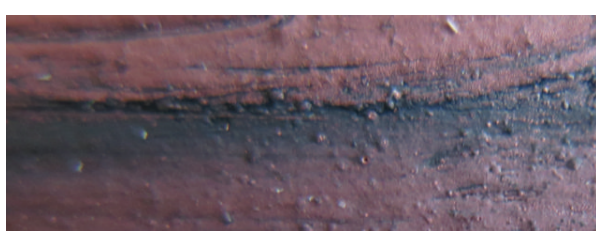

FIGURE 6: A close-up photo of partially sintered antenna in Sample 7.

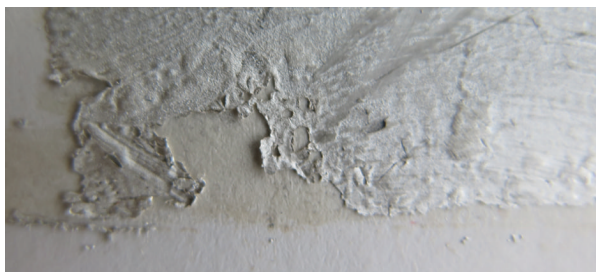

Figure 7: A close-up photo of burned antenna in Sample 13.

sample surface looked undersintered (see Figure 6) and hence it shows that even though the total amount of energy after 3 flash pulses is high enough, the sintering voltage is too low for this material combination.

The silver ink was found to be easily sintered also on cardboard substrate. Again, very minor variations in resistances were found, except for Sample $13(2000 \mu \mathrm{s}, 2800 \mathrm{~V}$, 1 flash pulse), which was not conductive at all. From Figure 7 it can be seen that the silver ink has burned away from parts of the cardboard substrate, meaning too high sintering energy per one flash pulse. Sample 13 had the highest light energy per one pulse (see Table 1) in this test lot with silver ink on card board substrate. Similar effect was seen in Sample 12 (2000 $\mu$ s, 2500 V, 2 flash pulses) but the burning of the ink layer was not as bad as in Sample 13 and the resistance result was good, $0.6 \Omega$. The light energy per one flash pulse was lower with sample 12 than with sample 13 . Samples 10 (1000 $\mu \mathrm{s}, 2800$ V, 3 flash pulses) and 11 (2000 $\mu$ s, $2200 \mathrm{~V}, 2$ flash pulses) were chosen for further measurements; their resistance measurement results were $0.6 \Omega$ and $0.7 \Omega$, respectively, even though marks of oversintering can also be seen in Sample 11.

As with copper ink on wood substrate, large variations in resistance results were found with copper ink on cardboard substrate. Sample 15 (2000 $\mu$ s, 2000 V, 2 flash pulses) and Sample $16(2000 \mu \mathrm{s}, 2200 \mathrm{~V}, 1$ flash pulse) with resistances of $9.7 \Omega$ and $5.8 \Omega$ were chosen to further measurements. In Sample 14 (1500 $\mu$ s, 2600 V, 1 flash pulse), Sample 17 (2000 $\mu \mathrm{s}$, 2200 V, 2 flash pulses), and Sample 18 (2000 $\mu$ s, 2400 V, 1 flash pulse) burned areas can be seen in visual inspection and this indicates that the sintering energy has been too high in these cases. Because of the results of visual inspection, further testing with 2 and 3 flash pulses was not done with these samples.

It has been found that if samples are overexposed to the xenon lamp, thus if too much energy is applied on the sample the sample is damaged and its electrical properties are decreased [26]. On the other hand if the light energy is 


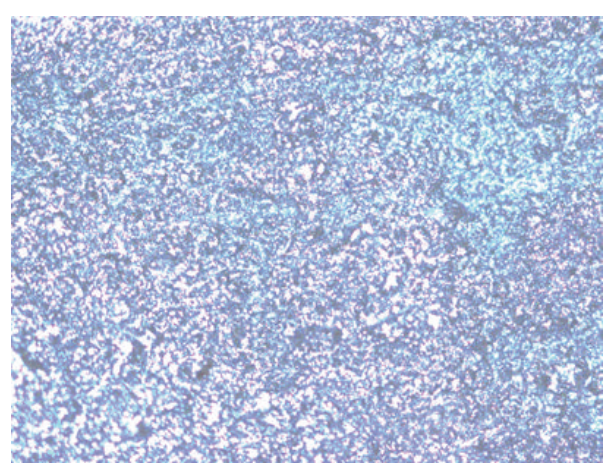

(a)

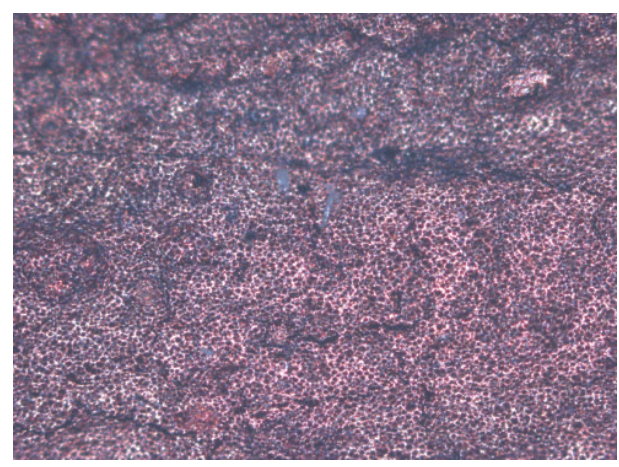

(b)

Figure 8: Optical microscope images (magnification $\times 5)$ of sintered silver $((a)$ Sample 4) and copper ((b) Sample 8) ink layers on wood substrate.

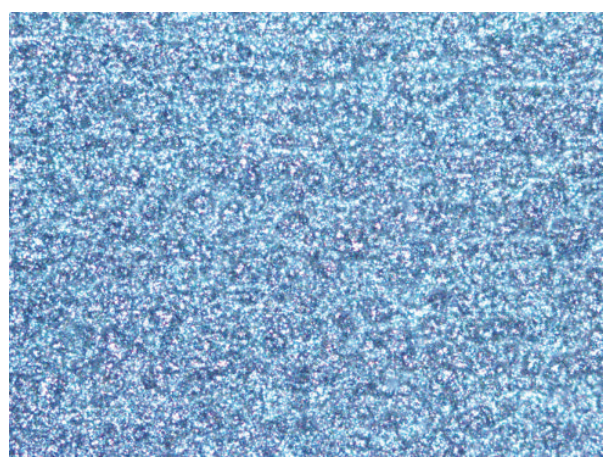

(a)

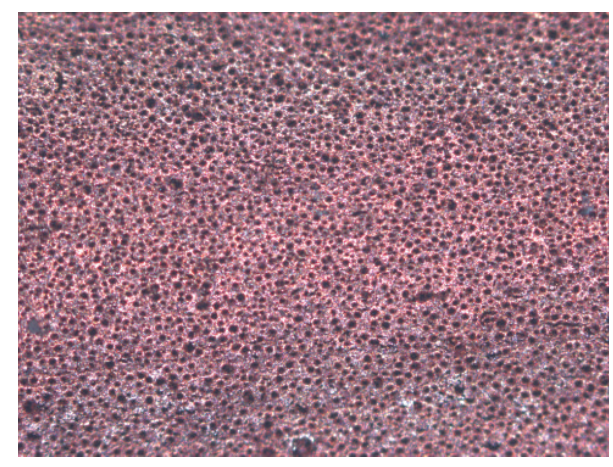

(b)

FIGURE 9: Optical microscope images (magnification $\times 5)$ of sintered silver ((a) Sample 10) and copper ((b) Sample 16) ink layers on cardboard substrate.

too low, the conductive ink pattern is not thoroughly sintered. The photonic sintering process goes from surface to deeper in the conductive ink layer [27]. If the sintering energy is too low, unsintered layers exist inside the antenna structure, causing performance degradation and total nonfunctioning, as seen, for example, with Sample 7.

Photonic sintering of the copper ink was found to be significantly more challenging than photonic sintering of the silver ink. The exact optimal parameters for copper oxide ink are much more significant for good conductivity than for silver ink and thus a wider range of sintering parameters can be used with silver ink than with copper oxide ink. This can also be seen in the results presented in Table 1. Optical microscope images of sintered silver and copper ink layers on wood and cardboard substrates can be seen in Figures 8 and 9 , respectively.

The tag IC utilized in this experiment was NXP UCODE G2iL series IC [28], which has a low wake-up power of $15.8 \mu \mathrm{W}(-18 \mathrm{dBm})$. The manufacturer had mounted the chip on a fixture with two $3 \times 3 \mathrm{~mm}^{2}$ pads which we connected to the antenna terminals using conductive epoxy (Circuit Works CW2400). However, when considering the future possibilities in RFID tag manufacturing, flip chip technology together with anisotropic conductive adhesives could make the fabrication process of environmentally friendly tags even faster.

\section{Wireless Testing of the Tags}

The manufactured tags were measured using Voyantic Tagformance measurement system [29] to conduct the measurement through a range of frequencies from $800 \mathrm{MHz}$ to $1000 \mathrm{MHz}$. The core operations are performed with a vector signal analyzer. Two key properties of passive UHF RFID tags, threshold power and theoretical read range, were measured as a function of transmit frequency.

Threshold power describes the minimum transmit power, at the transmit port, to activate the tag and can be expressed as

$$
P_{\mathrm{TS}}=\frac{P_{\mathrm{IC}}}{G_{\mathrm{tx}} G_{\mathrm{tag}} \tau(\lambda / 4 \pi d)^{2}\left|p_{\mathrm{tx}}^{\wedge} \cdot p_{\mathrm{tag}}^{\wedge}\right|^{2}},
$$

where $P_{\mathrm{IC}}$ is the sensitivity of the RFID IC, $G_{\mathrm{tx}}$ and $G_{\mathrm{tag}}$ are the gains of the reader and tag antenna, $\tau$ is the power transmission coefficient, $d$ is the distance between the tag and reader antenna, and $p_{\mathrm{tx}}$ and $p_{\mathrm{tag}}$ the unit electric field vectors of the transmitting antenna and tag antenna. The 


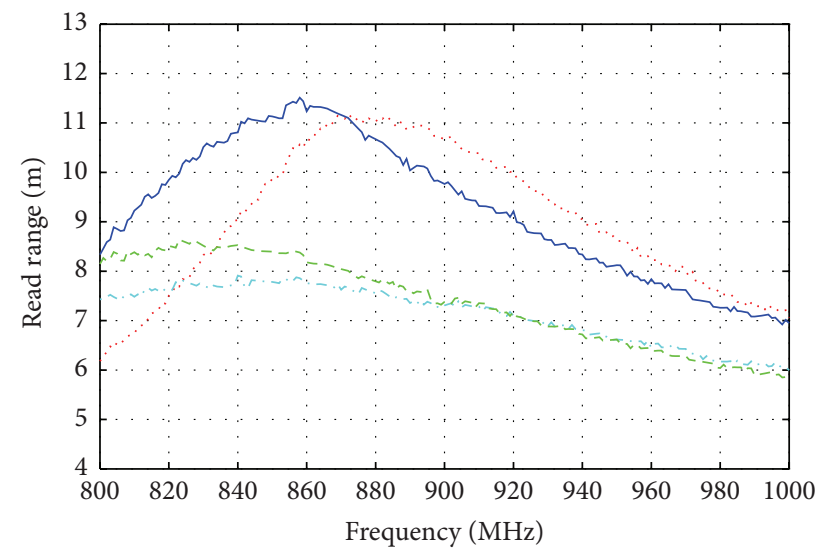

T2000/V3000 $\times 1$ Ag wood . - T $1500 / V 2600 \times 1 \mathrm{Cu}$ wood T2000/V2800 $\times 1$ Ag wood _ - T T2000/V2400 $\times 1 \mathrm{Cu}$ wood

Figure 10: Attainable read ranges of copper and silver tags on wood substrates.

inner product of the electric field vectors describes the power loss due to possibly mismatched polarization planes between the reader and tag antenna.

Theoretical read range describes the maximal distance between the tag and reader antenna in an environment without reflections or external disturbances. The Tagformance measurement system is able to calculate the theoretical read range of a tag using its measured threshold power along with the measured forward losses. The forward loss describes the link loss between the generator's output port and the input port of an equivalent isotropic antenna placed at the tag's location. The forward loss from the transmit port to the tag is calculated using a reference tag during the calibration procedure of Tagformance. Theoretical read range is calculated assuming that the read range is limited by the maximal allowed transmitted power levels and can be calculated as

$$
d_{\mathrm{tag}}=\frac{\lambda}{4 \pi} \sqrt{\frac{\mathrm{EIRP}}{P_{\mathrm{TS}} L_{\mathrm{fwd}}}},
$$

where $\lambda$ is the wavelength transmitted from the reader, EIRP is the maximum equivalent isotropically radiated power allowed by local regulations, $3.28 \mathrm{~W}$ in Europe, and $P_{\mathrm{TS}}$ and $L_{\text {fwd }}$ are the measured threshold power and forward losses correspondingly.

\section{Wireless Measurement Results}

Figures 10 and 11 show the attainable read ranges for copper and silver tags on wood and cardboard substrates, respectively. It can be seen that the silver tags on both substrates perform very well. The attainable peak read ranges for silver tags on wood substrate are over 11 meters and for cardboard substrate over 12 meters. The read ranges through the global UHF RFID band are over 7 meters for silver tags on wood substrate and over 6.5 meters for the silver tags on cardboard substrates.

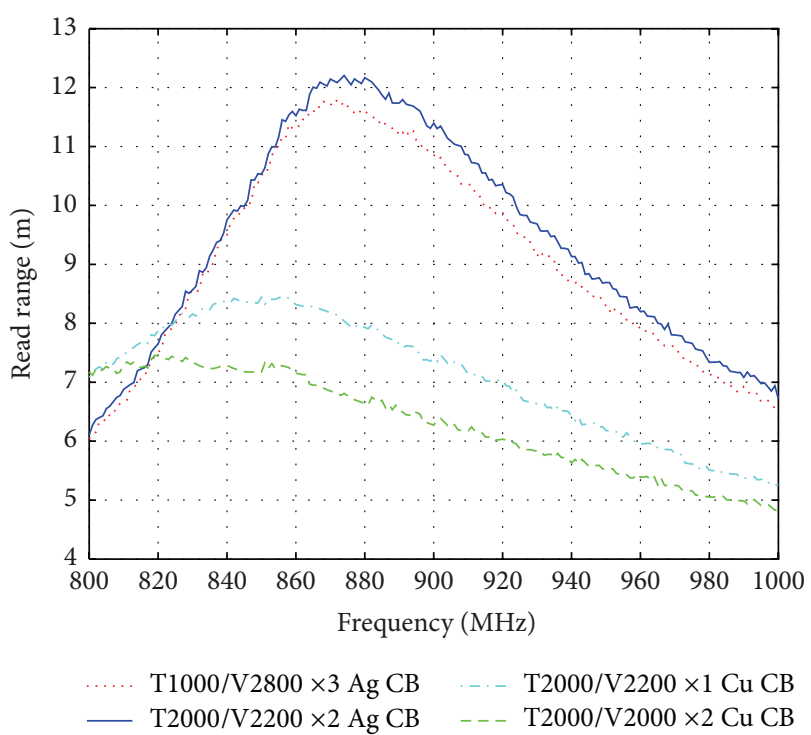

FIgURE 11: Attainable read ranges of copper and silver tags on cardboard substrates.

As expected, based on the resistance measurements, the copper tag read ranges are shorter than the silver tag read ranges. The attainable peak read ranges for copper tags on wood and cardboard substrates are over 8.5 meters. Through the global UHF RFID band the read ranges are over 6 meters and 5 meters for copper tags on wood and cardboard substrates, respectively.

The brush-painting of silver and copper nanoparticle inks on wood substrate has been reported in our previous study [2], where the same tag antenna geometry was brush-painted on wood and photonically sintered. The peak read ranges for tags with silver and copper nanoparticle ink antennas on wood substrate were about 5 meters and 3.5 meters, respectively [2]. In another study, inkjet-printed and heatsintered silver nanoparticle tags on wood veneer with similar tag antenna geometry achieved peak read ranges of 6.5 meters and read ranges of over 2 meters throughout the global UHF RFID band [7]. In this study we achieved read ranges of over 11 meters with silver ink and over 8 meters with copper oxide ink on wood substrate by using screen printable inks.

These results indicate that the use of normal screen printable conductive ink is more beneficial than the use of nanoparticle conductive ink on wood substrate and that the brush-painted antennas offer an alternative to inkjet-printed and screen-printed antennas on biodegradable, environment-friendly substrates. It should be noted that the brush-painting method is not suitable for structures containing very small details; if very minor dimensions are required, inkjet printing is recommended. However, with basic geometries, it is possible to achieve RFID antennas with suitable read ranges by only one brushed layer. The read ranges of few meters are sufficient, for example, for identification purposes in the construction and packaging industry, and much longer read ranges would not give significant benefits to supply chain management or for identifying products during field use and after-sales services. 


\section{Conclusions}

In this paper, we present a novel brush-painting method for depositing copper and silver conductive inks directly on wood and cardboard substrates. The method has a great potential to simplify manufacturing of wireless components. The optimal parameters for photonic sintering of copper oxide and silver inks on these substrates were studied and they were used to manufacture passive UHF RFID tag antennas. The manufactured copper and silver tags on wood substrate showed peak attainable read ranges of over 8.5 and 11 meters, respectively, and on cardboard substrate over 8.5 and 12 meters, respectively. Moreover, all of the tags exhibited read ranges of several meters throughout the whole global UHRF RFID band. These results offer a huge potential for applications in versatile industries requiring remote identification with RFID. Brush-painting with photonic sintering can be integrated into manufacturing process of RFID tags, which means the method has a great potential in manufacturing of environmentally friendly wireless components. In future, the authors will also study the possibilities of simulations with the manufacturing method presented in this study.

\section{Competing Interests}

None of the authors has any conflict of interests.

\section{References}

[1] J. Virkki, T. Björninen, L. Sydänheimo, and L. Ukkonen, "Brush-painted silver nanoparticle UHF RFID tags on fabric substrates," in Proceedings of the Progress in Electromagnetics Research Symposium (PIERS '14), pp. 2106-2110, Guangzhou, China, August 2014

[2] E. Sipila, J. Virkki, L. Sydanheimo, and L. Ukkonen, "Experimental study on brush-painted metallic nanoparticle UHF RFID tags on wood substrates," IEEE Antennas and Wireless Propagation Letters, vol. 14, pp. 301-304, 2015.

[3] J. Virtanen, J. Virkki, A. Z. Elsherbeni, L. Sydänheimo, and L. Ukkonen, "A selective ink deposition method for the costperformance optimization of inkjet-printed UHF RFID tag antennas," International Journal of Antennas and Propagation, vol. 2012, Article ID 801014, 9 pages, 2012.

[4] G. Orecchini, F. Alimenti, V. Palazzari, A. Rida, M. M. Tentzeris, and L. Roselli, "Design and fabrication of ultra-low cost radio frequency identification antennas and tags exploiting paper substrates and inkjet printing technology," IET Microwaves, Antennas \& Propagation, vol. 5, no. 8, pp. 993-1001, 2011.

[5] M. M. Tentzeris, L. Yang, A. Rida, A. Traille, R. Vyas, and T. Wu, "Inkjet-printed RFID tags on paper-based substrates for UHF 'cognitive intelligence' applications,' in Proceedings of the 18th Annual IEEE International Symposium on Personal, Indoor and Mobile Radio Communications (PIMRC '07), pp. 1-4, Athens, Greece, September 2007.

[6] S. L. Merilampi, J. Virkki, L. Ukkonen, and L. Sydänheimo, "Testing the effects of temperature and humidity on printed passive UHF RFID tags on paper substrate," International Journal of Electronics, vol. 101, no. 5, pp. 711-730, 2014.
[7] J. Virtanen, J. Virkki, L. Sydänheimo, M. M. Tentzeris, and L. Ukkonen, "Automated identification of plywood using embedded inkjet-printed passive UHF RFID tags," IEEE Transactions on Automation Science and Engineering, vol. 10, no. 3, pp. 796806, 2013.

[8] J. Virkki, S. Merilampi, L. Ukkonen, and L. Sydänheimo, "Performance of UHF RFID tags printed directly on plywood structures," International Journal of RF Technologies, vol. 3, no. 4, pp. 283-302, 2012.

[9] K. Finkenzeller, RFID Handbook: Fundamentals and Applications in Contactless Smart Cards and Identification, John Wiley \& Sons, Chichester, UK, 2nd edition, 2003.

[10] G. Marrocco, "Pervasive electromagnetics: sensing paradigms by passive RFID technology," IEEE Wireless Communications, vol. 17, no. 6, pp. 10-17, 2010.

[11] E. Welbourne, L. Battle, G. Cole et al., "Building the internet of things using RFID," IEEE Internet Computing, vol. 13, no. 3, pp. 48-55, 2009.

[12] J. Landt, “The history of RFID," IEEE Potentials, vol. 24, no. 4, pp. 8-11, 2005.

[13] R. Want, "An introduction to RFID technology," IEEE Pervasive Computing, vol. 5, no. 1, pp. 25-33, 2006.

[14] D. Dobkin, The RF in RFID: Passive UHF RFID in Practice, Newnes-Elsevier, 2008.

[15] G. Marrocco, "The art of UHF RFID antenna design: impedance-matching and size-reduction techniques," IEEE Antennas and Propagation Magazine, vol. 50, no. 1, pp. 66-79, 2008.

[16] E. Perret, S. Tedjini, and R. S. Nair, "Design of antennas for UHF RFID tags," Proceedings of the IEEE, vol. 100, no. 7, pp. 23302340, 2012.

[17] J. Virkki, S. Merilampi, L. Ukkonen, and L. Sydänheimo, "Performance of UHF RFID tags printed directly on plywood structures," International Journal of RF Technologies: Research and Applications, vol. 3, no. 4, pp. 283-302, 2012.

[18] Metalon HPS-021LV Silver Screen Ink, April 2016, http://store novacentrix.com/v/vspfiles/assets/images/metalon $\% 20 \mathrm{hps-}$ 021lv_2230.1.pdf.

[19] Metalon ICI-021 Copper Oxide Screen Ink, April 2016, https:// store.novacentrix.com/v/vspfiles/assets/images/metalon\%20ici021\%202229.1.pdf.

[20] H.-S. Kim, S. R. Dhage, D.-E. Shim, and H. T. Hahn, "Intense pulsed light sintering of copper nanoink for printed electronics," Applied Physics A: Materials Science \& Processing, vol. 97, no. 4, pp. 791-798, 2009.

[21] B. Polzinger, F. Schoen, V. Matic et al., "UV-sintering of inkjetprinted conductive silver tracks," in Proceedings of the 11th IEEE International Conference on Nanotechnology (NANO '11), pp. 201-204, Portland, Ore, USA, August 2011.

[22] J. Ryu, H.-S. Kim, and H. T. Hahn, "Reactive sintering of copper nanoparticles using intense pulsed light for printed electronics," Journal of Electronic Materials, vol. 40, no. 1, pp. 42-50, 2011.

[23] S.-H. Park, W.-H. Chung, and H.-S. Kim, "Temperature changes of copper nanoparticle ink during flash light sintering," Journal of Materials Processing Technology, vol. 214, no. 11, pp. 27302738,2014

[24] Xenon Sinteron 2010-L Installation and User Manual, Xenon Corporation, 2013.

[25] K. A. Schroder, S. C. McCool, and W. F. Furlan, "Broadcast photonic curing of metallic nanoparticle films," in Proceedings of the NSTI Nanotechnology Conference and Trade Show, vol. 3, pp. 198-201, Boston, Mass, USA, May 2006. 
[26] S. Lim, M. Joyce, P. D. Fleming, and A. T. Aijazi, "Inkjet printing and sintering of nano-copper ink," Journal of Imaging Science and Technology, vol. 57, no. 5, pp. 50506-1-50506-7, 2013.

[27] D. J. Lee, S. H. Park, S. Jang, H. S. Kim, J. H. Oh, and Y. W. Song, "Pulsed light sintering characteristics of inkjetprinted nanosilver films on a polymer substrate," Journal of Micromechanics and Microengineering, vol. 21, no. 12, Article ID 125023, 2011.

[28] NXP UCODE G2iL IC, April 2016, http://www.nxp.com/documents/data_sheet/SL3S1203_1213.pdf.

[29] Voyantic Ltd., Espoo, Finland, May 2015, http://www.voyantic .com/. 


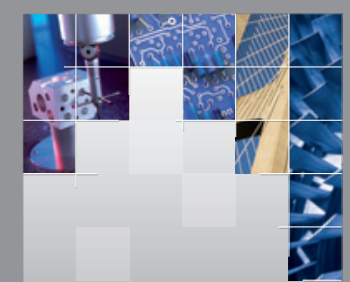

\section{Enfincering}
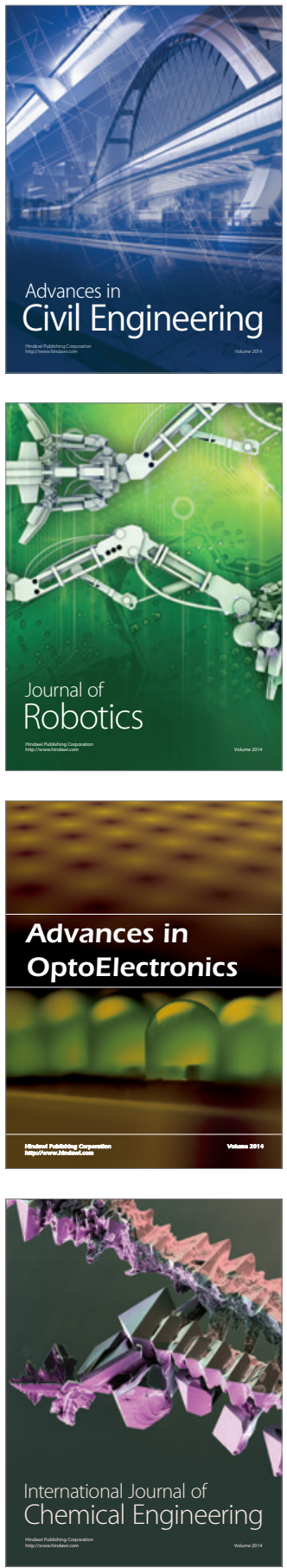

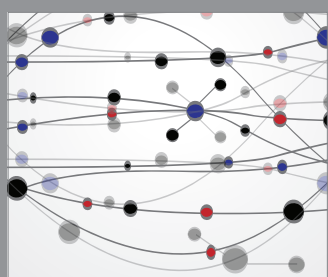

The Scientific World Journal

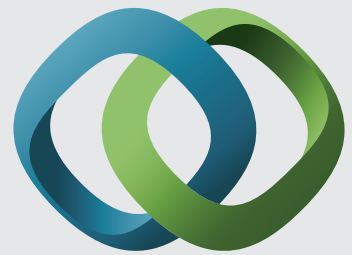

\section{Hindawi}

Submit your manuscripts at

http://www.hindawi.com
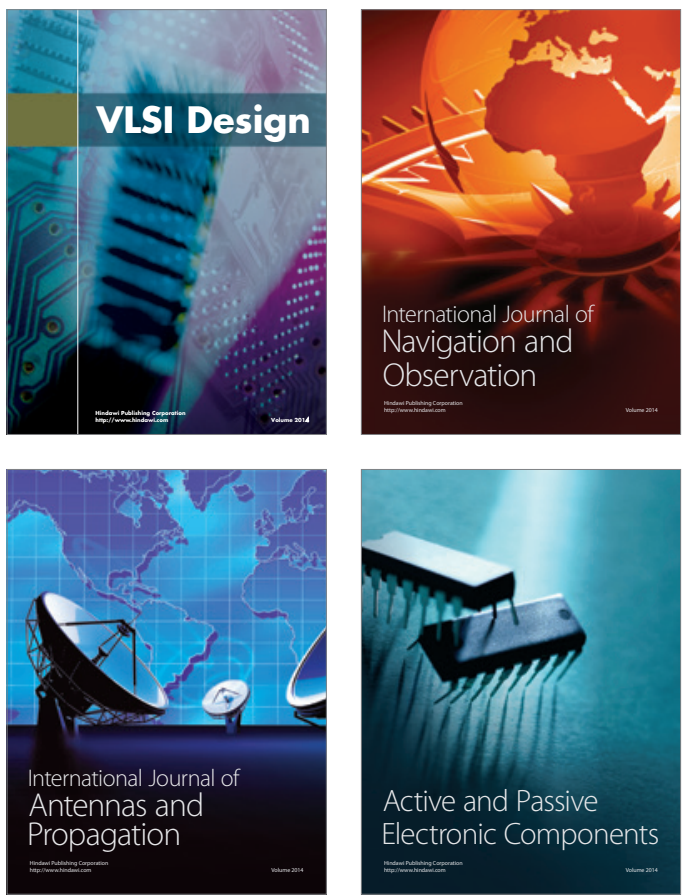
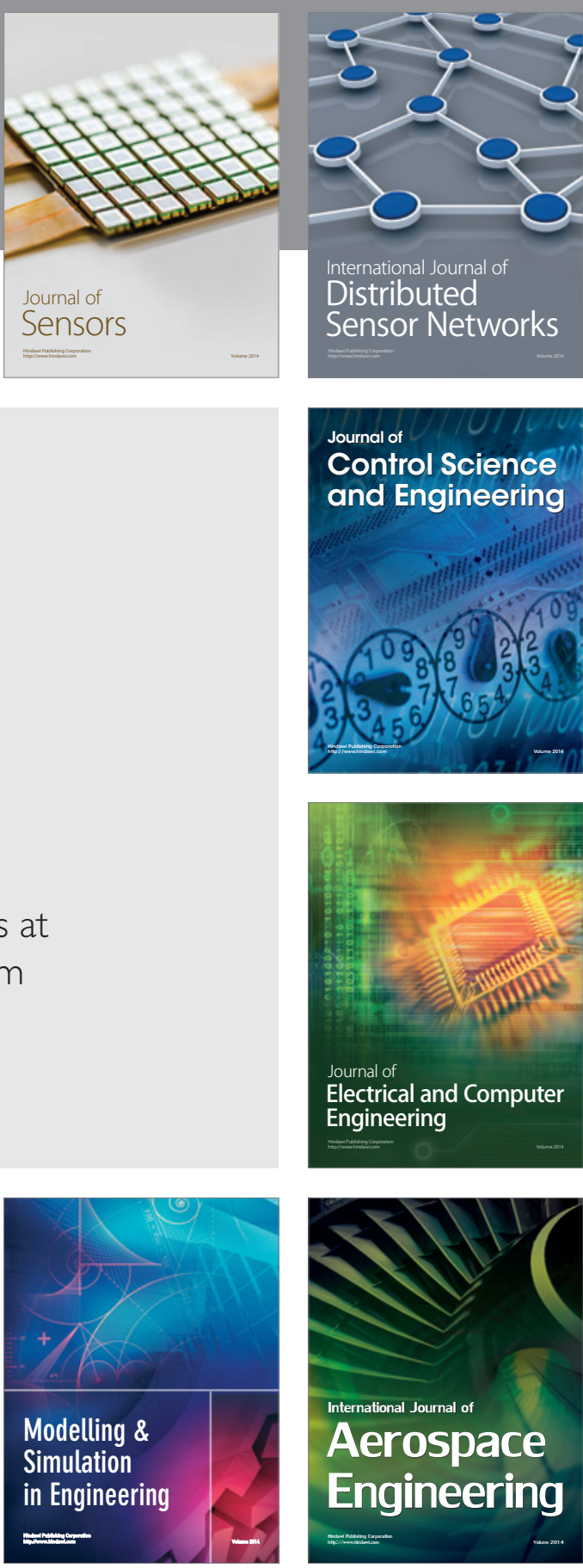

International Journal of

Distributed

Sensor Networks

Journal of

Control Science

and Engineering
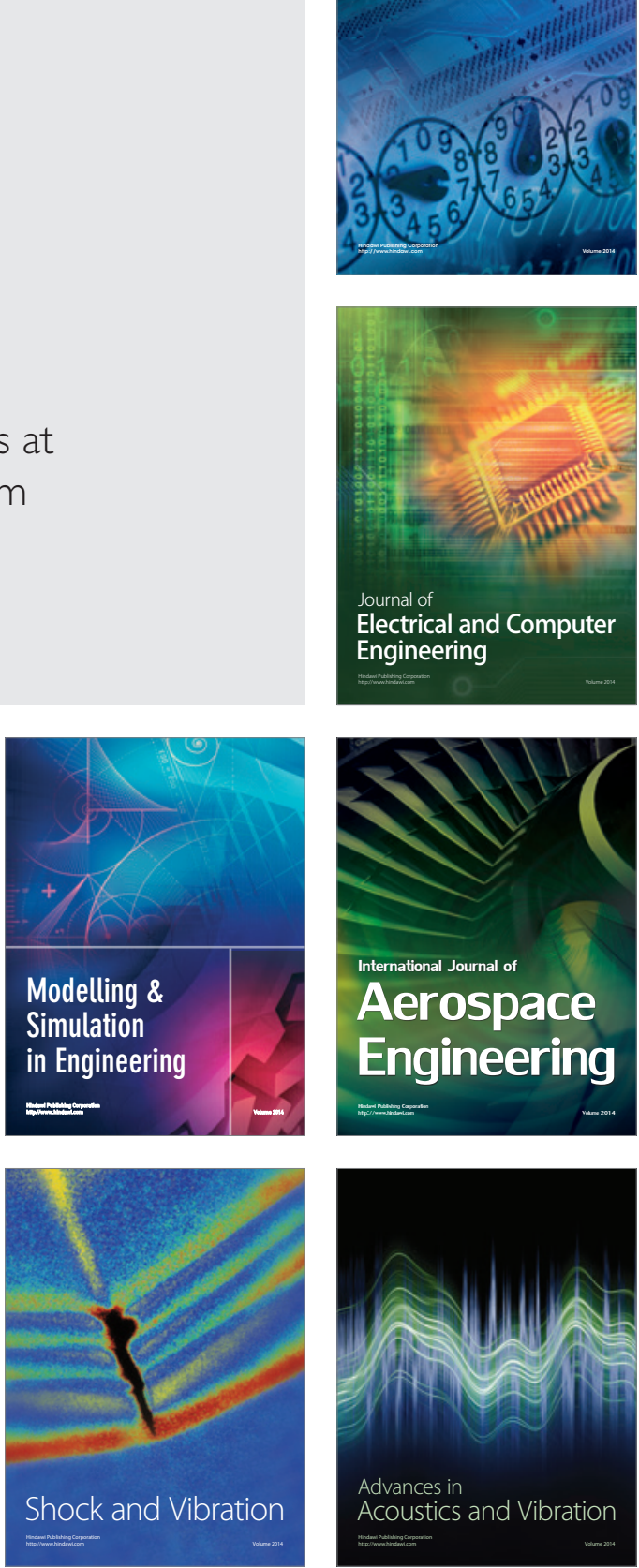